\title{
Fracture Behavior of Polymeric Fiber Reinforced Lightweight Structural Concrete
}

\author{
Itamar de Freitas ${ }^{a}$, Fathi Darwish $^{a}$, Marcos Venicius Pereira ${ }^{b *}$, Katia Allende $^{a}$ \\ ${ }^{a}$ Department of Civil Engineering, Fluminense Federal University, Rua Passo da Pátria, 156, \\ CEP 24210-240, Niterói, RJ, Brazil \\ ${ }^{b}$ Department of Materials Engineering, Catholic University of Rio de Janeiro, Rua Marquês de \\ São Vicente, 225, CEP 22453-900, Rio de Janeiro, RJ, Brazil
}

Received: April 4, 2014; Revised: November 21, 2014

\begin{abstract}
A study has been made of the effect of short randomly dispersed polypropylene fibers on the fracture behavior of lightweight structural concrete. Using unnotched and precracked beams subjected to bend loading, it was possible to determine the toughness factor $T F$ and to estimate specific J integral parameters, namely $J_{I C}$ and $J_{M A X}$ corresponding to the onset of fracture initiation and to the attainment of ultimate load, respectively. The results have indicated a considerable improvement in the fracture behavior associated with the presence of fibers. More specifically this improvement was manifested by a $400 \%$ increase in both $T F$ and $J_{I C}$.
\end{abstract}

Keywords: lightweight concrete, fracture initiation, J integral, toughness factor, compressive strength

\section{Introduction}

Cementitious materials, such as concrete and cement mortar, are characterized by low tensile strength and poor fracture toughness. Particularly, for high strength concrete, poor toughness represents a serious shortcoming that can be overcome by dispersing short discontinuous fibers throughout the cementitious matrix ${ }^{1}$. The fibers primarily control the propagation of cracks and limit crack width ${ }^{2}$, which promotes the toughness of the fiber reinforced concrete.

Mechanical properties, namely, compressive strength, split tensile strength, flexural strength and flexural toughness were studied for high strength concrete reinforced ${ }^{1}$, up to a volume fraction of $0.5 \%$, by hybrid combinations of steel and nonmetallic fibers such as glass, polyester and polypropylene. The presence of fibers was seen to enhance pre-peak as well as post-peak region of the load-deflection curve, causing an increase in flexural strength and toughness of the concrete, respectively. Whereas the addition of the steel fibers generally contributed to the energy absorbing mechanism (bridging action), the nonmetallic fibers resulted in delaying microcrack formation ${ }^{1}$.

In a recent study ${ }^{3}$, very high strength concrete panels had their tensile strength and fracture toughness significantly increased by the incorporation of polypropylene fibers at $1.5 \%$ by volume. Without the addition of fibers, the concrete behaved, essentially, in a linear elastic and brittle mode, with a complete loss of tensile stress upon first cracking. The presence of the short randomly distributed fibers had a beneficial effect on the post-crack behavior, promoting the concrete's ductility and toughness ${ }^{3}$. Observing the three point bend loading curves, three distinct phases of flexural response could be distinguished:

*e-mail: marcospe@puc-rio.br
- initial response characterized by a linear loaddeflection behavior, presumably up to first crack load;

- second stage of the load-deflection curve corresponding to sharp transition into a ductile response and progressing to the ultimate load;

- third stage with the composite failing abruptly with the development of a single macrocrack and a swift loss of load resistance / or with a small residual load carrying capacity ${ }^{3}$.

In addition to metallic and polymeric fibers, natural fibers, such as sisal and bamboo, have also been proposed as reinforcing elements in cementitious materials. A number of studies were carried out in order to evaluate the mechanical properties of the produced composites ${ }^{4-8}$, and the results indicated the viability of using such fibers as reinforcing elements. Despite a tolerable degradation in the compressive strength, flexural strength and fracture toughness were significantly enhanced due to the presence of fibers in the cementitious matrix, consistent with experimental data reported by Abu-Lebdeh et al. ${ }^{3}$. It is to be noted, though, that the susceptibility of natural fibers to degradation, due to ambient and biological factors, requires appropriate surface treatment in order to improve their durability.

The present work was initiated with the purpose of evaluating the effect of the presence of short randomly dispersed polypropylene fibers on the toughness of hardened lightweight concrete. Different methodologies for toughness testing were adopted and appropriate toughness parameters were determined for the fiber reinforced concrete, which were then compared with those of the concrete in the absence of fibers. The toughness levels are presented and discussed focusing on the comparison between the test methods and on the influence of fiber presence in improving fracture behavior of the concrete. 


\section{Material and Methods}

\subsection{Concrete preparation}

Using Portland cement, PC II E 32, trial concrete mixtures were prepared targeting a compressive strength level of $30 \mathrm{MPa}$ at 28 days. Washed dry river sand was used as fine aggregate, while expanded clay was used as coarse aggregate. An aromatic polynaphthalene based superplasticizer was added to the mixture so as to insure adequate workability.

The detailed composition of the mixture selected for the study is presented in Table 1 . The relatively high proportions of cement and sand shown in this table imply in a correspondingly high volume fraction of cement mortar, thus favoring a uniform distribution of fibers throughout the hardened concrete.

The expanded clay used as lightweight coarse aggregate had an apparent density of $380 \mathrm{~kg} / \mathrm{m}^{3}$ and was composed of rounded particles ( $9.5 \mathrm{~mm}$ maximum diameter), with a vitrified, almost impermeable, surface. The sand used as fine aggregate had a fineness modulus of about 3.33, a maximum particle diameter of $2.38 \mathrm{~mm}$ and an apparent density of 1.6 $\mathrm{g} / \mathrm{cm}^{3}$. As to the polypropylene fibers, these were $100 \mathrm{~mm}$ in diameter and about $50 \mathrm{~mm}$ in length, with a corresponding aspect ratio of 500 and density of $0.91 \mathrm{~g} / \mathrm{cm}^{3}$ (in fact, a mass of one $\mathrm{kg}$ was found to contain about $2.8 \times 10^{6}$ fibers). Its modulus of elasticity is situated at about $4 \mathrm{GPa}$.

Homogenization of the concrete mixture was carried out using a slow rotating vertical propeller and no significant segregation of expanded clay was observed. Visual examination of fractured hardened concrete specimens indicated good adherence between the expanded clay particles and the cement/sand mortar.

As to the production of the reinforced concrete, the polypropylene fibers were added gradually, along the homogenization process, in the proportion of $2.5 \%$ of the cement weight. This proportion, which amounts to a total fiber volume fraction of approximately $1.7 \%$, was defined considering the necessity of maintaining the level of the concrete compressive strength within acceptable limits. By thorough mixing of such a proportion during the homogenization process, it was possible to obtain a uniform distribution of fiber throughout the cement/sand binder, as could be attested by examining fractured pieces of the hardened concrete.

\subsection{Porosity evaluation}

The porosity index $(\gamma)$ as defined by the volume fraction of permeable pores contained in a specimen of hardened concrete was determined according to $\mathrm{ABNT}^{9}$, by means of Equation 1:

$\gamma=\frac{M s a t-M s}{M s a t-M i}$ where $M_{S A T}$ is the water-saturated specimen weight, $M_{S}$ the weight of dry specimen and $M_{I}$ the weight of water-saturated specimen immersed in water.

Using Equation 1, it was verified that the incorporation of polypropylene fibers into the concrete mixture results in a porosity index of about 0.11 as compared to 0.09 for plain concrete.

\subsection{Mechanical tests}

Compression tests were carried out to determine the compressive strength $f_{C}$, modulus of elasticity $E$ and Poisson's ratio v, using cylindrical specimens cast from the plain and fiber reinforced concrete mixtures. Fracture testing, on the other hand, was aimed at evaluating the toughness of both cast materials by adopting three different methodologies. The first method, which is based on linear elastic fracture mechanics, makes use of a precracked cylindrical specimen (see Figure 1) to be loaded in diametrical compression.

The critical stress intensity factor $K_{I C}$ can be estimated from Equation $2^{10}$ :

$K_{I c}=\frac{2 P_{\max }}{L D} \sqrt{\frac{a}{\pi}} f(2 \mathrm{a} / \mathrm{D})$

where $P_{M A X}$ is the maximum load. The dimensions $L, D$ and $a$, which are shown in Figure 1, are equal to 200, 100 and $17.5 \mathrm{~mm}$, respectively. The function $f$ for $2 a / D=0.35$ was taken as $1.20^{11}$ and the crack, which had a root radius of $1 \mathrm{~mm}$, was considered to be sufficiently sharp.

The second method ${ }^{12}$ is based on determining the work done $T_{B}$ on achieving a beam deflection equivalent to $\mathrm{L} / 150$ in four point bending of unnotched prismatic beams, as presented in Figure 2. This work, which is represented by the area under the load-deflection curve, can be used to calculate the toughness factor $T F$ by means of Equation $3^{12}$ :

$T F=\frac{T_{b}}{\delta_{t b}} \frac{L}{b h^{2}}$

where $L$ is the beam span, $b$ and $h$ are the dimensions of the beam cross section $(100 \times 100 \mathrm{~mm})$ and $\delta_{t b}$ is the beam deflection.

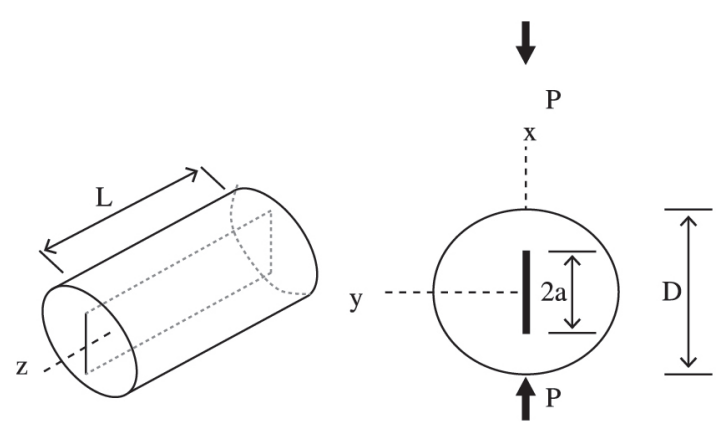

Figure 1. Geometry of the centrally cracked cylindrical specimens.

Table 1. Composition of the concrete mixture used in the study $\left(\mathrm{kg} / \mathrm{m}^{3}\right)$.

\begin{tabular}{cccccc}
\hline Cement & Silica fume & Sand & Expanded Clay & Water & Superplasticizer \\
\hline 608 & 49 & 570 & 240 & 231 & 12 \\
\hline
\end{tabular}


The third adopted approach, for toughness evaluation, is based on determining the J integral $(J)$ value corresponding to specific physically significant events observed during loading of precracked specimens. The specimens, which had the geometry and dimensions of the beam depicted in Figure 2, were precracked in its midsection to a crack-width ratio $a / W$ of 0.5 . The precracked beams were then subjected to four point bend loading and $J$ values were calculated using Rice's estimation formula ${ }^{13}$ (Equation 4):

$J=\frac{2 U}{B(W-a)}$

where $B$ and $W$ are the beam cross sectional dimensions, equivalent to $b$ and $h$ in Equation 3, respectively. The term $U$ in the above formula refers to the amount of energy stored in the beam for a given applied load, as for example fracture initiation load.

The precrack root radius amounted to $1 \mathrm{~mm}$, which, in virtue of the heterogeneous nature of the concrete and particle size of its aggregates, is considered to be sufficiently sharp and therefore the $J$ value corresponding to the onset of fracture initiation would seem to be a fairly good estimate of $J_{I C}$.

\section{Results and Discussion}

\subsection{Mechanical properties}

The values of $f_{C}, E$ and $v$ of the plain concrete are presented in Table 2, together with those corresponding to the fiber reinforced concrete. The $K_{I C}$ values obtained using Equation 2 are also listed in the same table.

These results indicate that the presence of fibers is associated with a reduction in concrete compressive strength and modulus of elasticity, which is in agreement with other studies ${ }^{4,8,14}$ made on the use of polymeric and natural fibers. This is attributed to the fact that polypropylene fibers are much less rigid than the cement mortar, which, in an isostrain compressive loading mode, should lead to a degradation

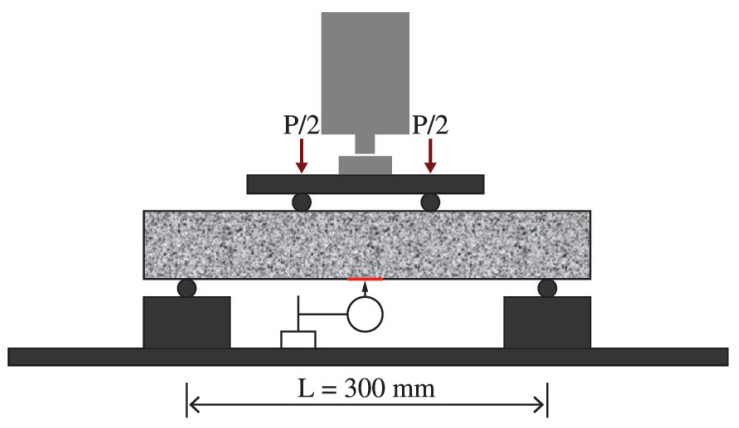

Figure 2. Schematic of the setup used for four point loading of the concrete beams. of the concrete strength level. More rigid fibers, such as steel for example, are expected, as reported by a number of authors ${ }^{1,14-17}$, to enhance the concrete compressive strength.

Another important factor that should be taken into account refers to the presence of pores, and hence the higher porosity index associated with the incorporation of polypropylene fibers also contributes to lowering the fiber reinforced concrete strength.

\subsection{Concrete toughness}

Examples of the loading curves obtained in diametrical compression are presented in Figure 3, where one can verify the marked influence of fiber presence on the concrete behavior. Whereas rupture of the plain concrete occurred in an unstable manner, the reinforced concrete continued to deform with a gradual drop in the applied load. In other words, the presence of polypropylene fibers in the concrete enhances the post-peak region of the load-deflection curve with no deleterious effect on the load carrying capacity of the precracked cylindrical specimens tested in diametrical compression. As the stress developed in the vicinity of the crack tip, perpendicular to the crack plane, is tensile in nature $^{18}$, the onset of cracking in the concrete is expected to invoke energy absorbing mechanism (fiber bridging action). As a result the load carrying capacity is preserved and the specimens continue to deform after achieving the maximum load, as can be observed in Figure 3.

At this point, it is important to mention that Equation 2 can be considered applicable to the plain concrete, as its loading curves are essentially linear elastic. However, this cannot be stated with regard to the fiber reinforced concrete, given its nonlinear behavior as exhibited in Figure 3 and therefore the corresponding $K_{I C}$ value listed in Table 2 does not reflect the reality of the fracture behavior. A more realistic estimate of the fracture toughness in this case may be obtained by substituting $P_{M A X}$ in Equation 2 by $P_{M A X}$ given by Equation 5:

$$
P_{\text {máx }}^{\prime}=\left(\frac{2}{C} \int_{0}^{\delta_{m}} P d \delta\right)^{1 / 2}
$$

where $C$ is the specimen compliance represented by the inverse of the gradient of the linear part of the $P-\delta$ curve and $d_{M}$ is the load displacement corresponding to $P_{M A X}$. It is important to mention that $P^{\prime}{ }_{M A X}$ corresponds to hypothetical maximum load that would be achieved if the concrete were to have a linear elastic behavior.

Taking into account the fact that the compliance of the fiber reinforced specimens tested in diametrical compression is approximately equal to $5 \times 10^{-3} \mathrm{~mm} / \mathrm{kN}$ and that the integral in the above equation has an average value of about $14.4 \mathrm{~J}$, the equivalent maximum load $P^{\text {' }}{ }_{\text {MAX }}$ was calculated as $76 \mathrm{kN}$. Such a load level yields an estimated $\mathrm{K}_{\mathrm{Ic}}$ value of about $0.68 \mathrm{MPa} \sqrt{\mathrm{m}}$.

Table 2. Mechanical properties for the concretes.

\begin{tabular}{ccccc}
\hline Concrete & $\boldsymbol{f}_{\boldsymbol{c}}(\mathbf{M P a})$ & $\boldsymbol{E}(\mathbf{G P a})$ & $\boldsymbol{v}$ & $\boldsymbol{K}_{\boldsymbol{I c}}(\mathbf{M P a} \sqrt{\mathbf{m}})$ \\
\hline Plain & $30 \pm 2.0$ & $27 \pm 1.5$ & 0.21 & $0.37 \pm 0.01$ \\
Reinforced & $24 \pm 1.0$ & $23 \pm 0.5$ & 0.25 & $0.36 \pm 0.02$ \\
\hline
\end{tabular}


A more adequate approach to establish a relevant comparison between the toughness values of fiber reinforced and plain concretes can be based on determining $T_{B}$ and then calculating $T F$ using Equation 3. Alternatively, one can adopt the $\mathrm{J}$ integral approach to estimate $J_{I C}$ and/or $J_{\text {MAX }}$ to be calculated for both materials by means of Equation 4 .

Examples of the load-deflection curves obtained on the basis of these two approaches are presented in Figures 4 and 5. Observing these curves, one can conclude that the flexural response of the plain concrete beams is limited to a single stage characterized, essentially, by a linear load-deflection behavior. The fiber reinforced beams, on the other hand, also exhibit a second stage corresponding to transition into a ductile response accompanied by an increase in the applied load, indicating that the incorporation of fibers is beneficial to the flexural strength and ductility and, therefore, to toughness of the concrete. This is attributed to strengthening and energy absorbing mechanisms $\mathrm{s}^{1-3}$ invoked by the flexural (tensile) stress acting in both precracked and uncracked bend loaded beams.

The values of $T_{B}, T F, J_{I C}, K_{I C}$ and $J_{M A X}$ are given in Table 3 for the concretes in question. One should point out that the $J_{I C}$ values listed in this table were estimated based on the assumption that the onset of fracture initiation in the reinforced concrete takes place essentially at the proportionality limit load. It is also to be added that $K_{I C}$ values were calculated from Equation 6:

$J_{I c}=\frac{K_{I c}^{2}\left(1-v^{2}\right)}{E}$

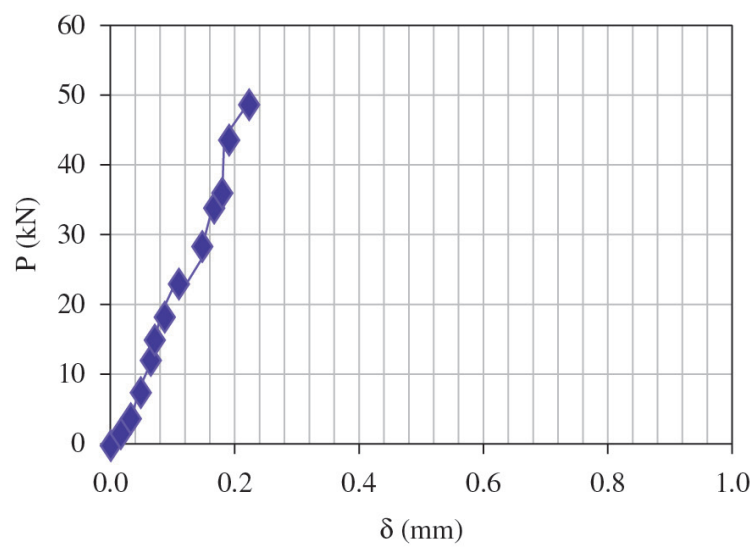

(a)

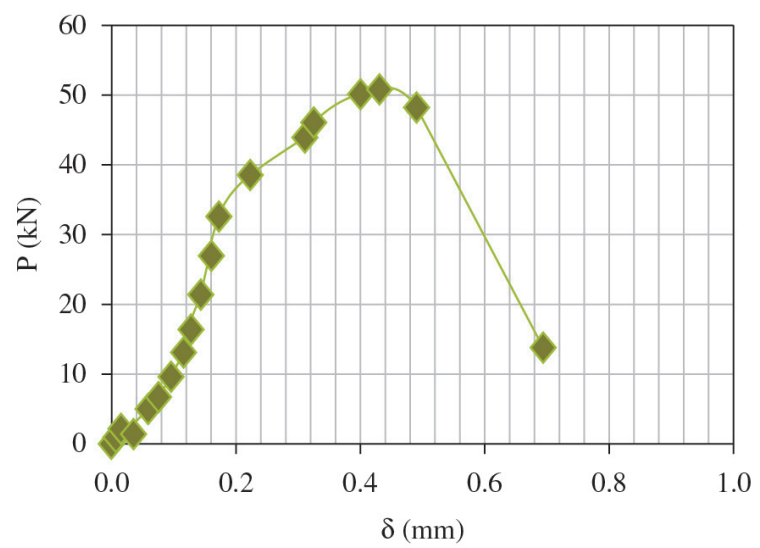

(b)

Figure 3. Load-deflection curves in diametrical compression for plain concrete (a) and fiber reinforced concrete (b).

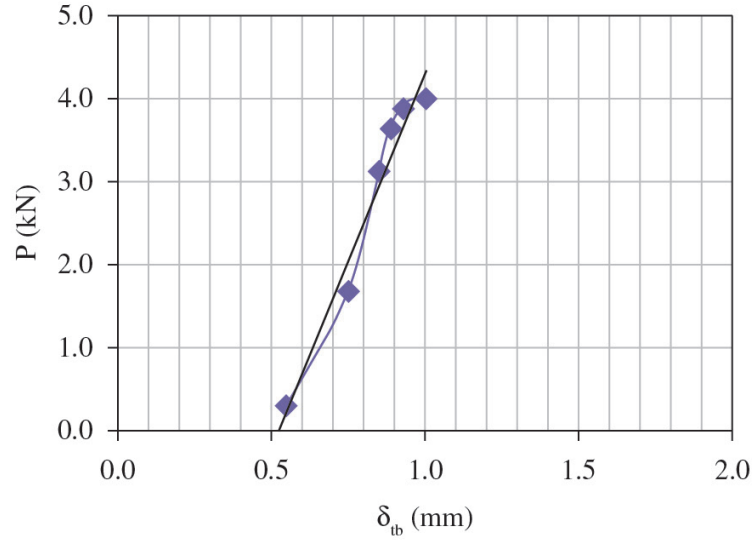

(a)

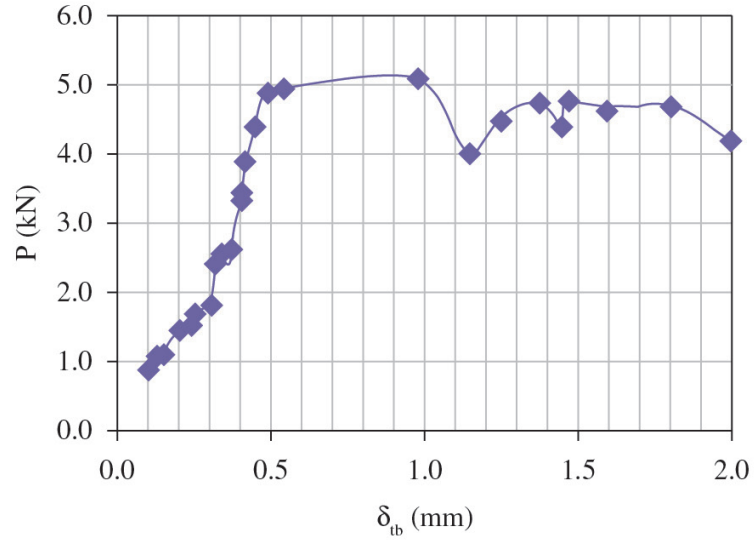

(b)

Figure 4. Typical load deflection curves obtained in four point bending of unnotched beams for plain concrete (a) and fiber reinforced concrete (b).

Table 3. Toughness parameters as determined for the concretes in question.

\begin{tabular}{cccccc}
\hline Concrete & $\boldsymbol{T}_{\boldsymbol{b}}(\mathbf{J})$ & $\boldsymbol{T F} \mathbf{( M P a )}$ & $\boldsymbol{J}_{I c}\left(\mathbf{J} / \mathbf{m}^{2}\right)$ & $\boldsymbol{K}_{I c}(\mathbf{M P a} \sqrt{\mathbf{m}})$ & $\boldsymbol{J}_{\boldsymbol{m}}\left(\mathbf{J} / \mathbf{m}^{2}\right)$ \\
\hline Plain & $1.12 \pm 0.23$ & $0.18 \pm 0.03$ & $68 \pm 12$ & 1.39 & $68 \pm 12$ \\
Reinforced & $5.00 \pm 1.12$ & $0.75 \pm 0.19$ & $306 \pm 106$ & 2.74 & $2916 \pm 700$ \\
\hline
\end{tabular}




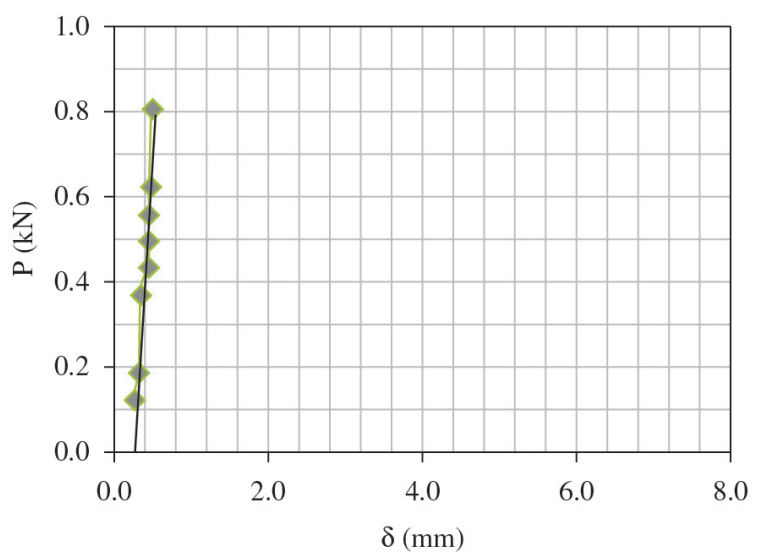

(a)

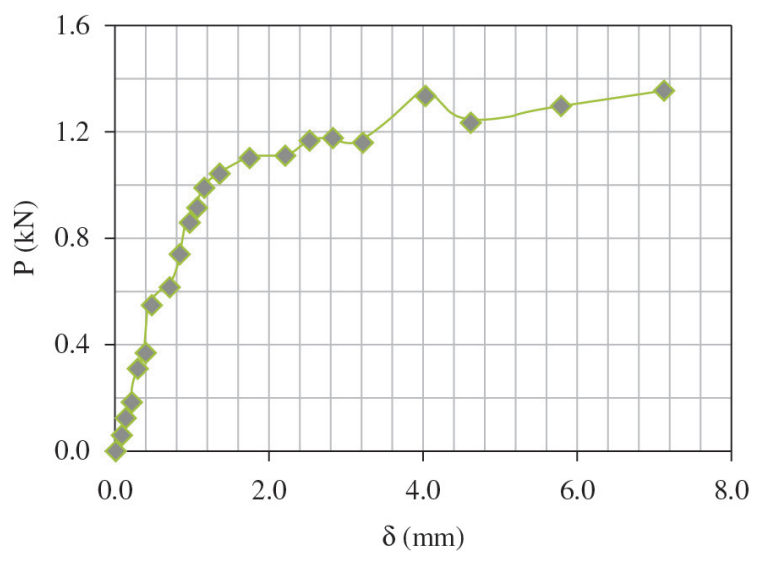

(b)

Figure 5. Typical load deflection curves obtained in four point bending of precracked beams for plain concrete (a) and fiber reinforced concrete (b).

One can observe from the data listed in Table 3 that both $T_{B}$ and $T F$ corresponding to the fiber reinforced concrete are more than four times greater than their respective plain concrete counterparts. As Figure 4a indicates, the $P-\delta$ curve does not exhibit a relevant second stage flexural response and fracture of plain concrete beams occurred at maximum load with a corresponding beam deflection amounting to about $0.5 \mathrm{~mm}$. With the inclusion of polypropylene fibers, the post-crack ductility improved considerably and a $\delta_{t b}$ level of $2 \mathrm{~mm}(=\mathrm{L} / 150)$ could be achieved as shown in Figure 4b. Additionally, as can be seen from Figure 4, this improvement was also accompanied by an increase in the load carrying capacity of the reinforced beams, leading to higher $T_{B}$ and $T F$ levels.

As fracture initiation presumably takes place at the onset of the second stage of the $P-\delta$ curve, one can conclude from Figure 5 that the initiation load is higher for the fiber reinforced concrete beams than for the plain concrete. Given the additional fact that the beam deflection at the initiation load is also higher in the presence of fibers, the energy term $U$, in Equation 4, and consequently $J_{I C}$ will be higher for the fiber reinforced concrete. Higher $J_{M A X}$ level, on the other hand, is evidently related to higher beam deflection corresponding to the maximum load. As the fibers play an important role in maintaining the integrity of loaded beams following matrix cracking, high $d_{M}$ levels are expected to be achieved in fiber reinforced concrete. This is borne out by the loading curves depicted in Figure 5 and by the $J$ values reported in Table 3.

Although a large degree of scatter characterizes the $\mathrm{J}$ integral results, they are seen to agree well with the

\section{References}

1. Sivakumar A and Santhanam M. Mechanical properties of high strength concrete reinforced with metallic and non-metallic fibers. Cement and Concrete Composites. 2007; 29(8):603-608. http://dx.doi.org/10.1016/j.cemconcomp.2007.03.006.

2. Qian CX and Stroeven P. Development of hybrid polypropylenesteel-fiber-reinforced concrete. Cement and Concrete results obtained from the unnotched four point loaded beams. Both results point out to the fact that the addition of polypropylene fibers to lightweight structural concrete results in a considerable increase in $J_{I C}, T_{B}$ and $T F$ parameters by a factor larger than four and also in achieving high $J_{M A X}$ levels, consistent with the increase in load carrying capacity as the beam continues to deform.

\section{Conclusions}

Based on the results obtained in the present study, the following conclusions can be drawn:

- The addition of short randomly oriented polypropylene fibers, in the proportion of 0.017 volume fraction, to lightweight concrete mixture results in a reduction of about $20 \%$ and $15 \%$ in the concrete axial compressive strength and modulus of elasticity respectively.

- The presence of the polypropylene fibers improves considerably the fracture behavior of the hardened concrete as a result of the enhancement of both its post-crack ductility and load carrying capacity.

- Toughness parameters obtained from bend tests of both unnotched and precracked beams are seen to be convergent. More specifically the results indicate a more than fourfold increase in the toughness factor $T F$ and the $J_{I C}$ parameter, in virtue of the presence of polypropylene fibers.

- As the fibers retard and thereafter control cracking of the concrete, the beam integrity is maintained and the $\mathrm{J}$ integral value at the maximum load is significantly increased due to fiber presence.
Research. 2000; 30(1):63-69. http://dx.doi.org/10.1016/S00088846(99)00202-1.

3. Abu-Lebdeh TM, Fini E and Lumpkin M. Flexural and tensile characteristics of microfiber-reinforced very high strength concrete thin panels. American Journal of Engineering and Applied Science. 2012; 5(2):184-197. http://dx.doi. org/10.3844/ajeassp.2012.184.197. 
4. Fujiyama RT. Sisal fiber reinforced cement mortar-mechanical and microstructural characterization. [Dissertation]. Rio de Janeiro: Catholic University of Rio de Janeiro; 1997. In Portuguese.

5. Brescansin J. Fracture behavior of bamboo pulp reinforced cementitious matrix. [Dissertation]. Rio de Janeiro: Catholic University of Rio de Janeiro; 2003. In Portuguese.

6. Sales ATC. Shrinkage, creep and fracture of bamboo pulp reinforced cementitious composite. [Thesis]. Rio de Janeiro: Catholic University of Rio de Janeiro; 2006. In Portuguese.

7. Campello EF. Fatigue behavior of bamboo pulp reinforced cementitious composites. [Dissertation]. Rio de Janeiro: Catholic University of Rio de Janeiro; 2006. In Portuguese.

8. Toledo RD. Natural fiber reinforced mortar composites: experimental characterization. [Thesis]. Rio de Janeiro: Catholic University of Rio de Janeiro; 1997.

9. Associação Brasileira de Normas Técnicas - ABNT. NBR 9779:1987: Argamassa e concreto endurecidos - Determinação da absorção da água por capilaridade - Método de ensaio. Rio de Janeiro; 1987.

10. Moseley MD, Ojdrovic RP and Petroski HJ. Influence of aggregate size on fracture toughness of concrete. Theoretical and Applied Fracture Mechanics. 1987; 7(3):207-210. http:// dx.doi.org/10.1016/0167-8442(87)90038-3.

11. Tada H, Paris PC and Irwin GR. The stress analysis of cracks handbook. St Louis: Paris Productions Incorporated; 1985.
12. Japan Society of Civil Engineers - JSCE. JSCE-SF4: Method of tests for flexural strength and flexural toughness of steel fiber reinforced concrete. Tokyo; 1984. Part III-2/3.

13. Rice JR. A path independent integral and the approximate analysis of strain concentrations by notches and cracks. Journal of Applied Mechanics. 1968; 35(2):379-386. http://dx.doi. org/10.1115/1.3601206.

14. Haktanir T, Ari K, Altun F, Atis CD and Karahan O. Effects of steel fibers and mineral filler on the water-tightness of concrete pipes. Cement and Concrete Composites. 2006; 28(9):811-816. http://dx.doi.org/10.1016/j.cemconcomp.2006.06.002.

15. Marara K, Erenb O and Yitmena I. Compression specific toughness of normal strength steel fiber reinforced concrete (NSSFRC) and high strength steel fiber reinforced concrete (HSSFRC). Materials Research. 2011; 14(2):239-247. http:// dx.doi.org/10.1590/S1516-14392011005000042.

16. Kitamura S. Experimental study of the influence of fiber content and specimen dimensions on the split tensile strength and its relationship with the flexural strength. [Dissertation]. Rio de Janeiro: Fluminense Federal University; 2006. In Portuguese.

17. Campello EF. Mechanical behavior of cement mortar reinforced by synthetic and metallic fibers. [Thesis]. Rio de Janeiro: Fluminense Federal University; 2012. In Portuguese.

18. Timoshenko SP and Goodier JN. Theory of elasticity. New York: McGraw-Hill; 1951. 